\title{
Decision support for building renovation strategies
}

\author{
Hang Yin
}

Department of Civil and Environmental Engineering, UCC

\section{Introduction}

In Europe, buildings account for $40 \%$ of energy consumption and $36 \%$ of $\mathrm{EU} \mathrm{CO}_{2}$ emissions. The energy usage of old structures built or rehabilitated before 1980 is as high as $300 \mathrm{kWh} / \mathrm{m}^{2} / \mathrm{yr}$, which is greater than the figure for modern structures and passive houses. Obviously, old buildings are the major users of energy, as they use more than twice as much as the modern building.

There are numerous published studies showing that energy savings of 40 to $74 \%$ can be achieved in commercial buildings through renovation. Implementing rational renovation, which results in efficient operation and maintenance and facilitates low energy consumption, creates a triple-win situation: it provides a much needed impetus to the European economy, it contributes to the achievements of energy and climate targets and it decreases energy costs for citizens, businesses and public bodies.

Normally, the renovation of existing buildings usually involves decision-making processes. The challenge is that there are too many alternatives to be considered and to be chosen. It is difficult to determine which low-energy technique has the best results for energy consumption and $\mathrm{CO}_{2}$ emissions. Therefore, it is necessary to analyse building performance and develop a decision support process for renovation strategies. This will be achieved through:

$\square$ Developing the Decision Support Framework (DSF) for building renovation strategies. The DSF proposes methodologies for the analysis of building performance and a Decision Support Model (DSM) for the process of decision-making.

$\square$ Developing methodologies for the analysis of building performance that is the integration of 'model-driven' and 'data-driven' in the framework.

Developing the DSM for the process of decision-making, which is the decision component of the framework.

$\square$ Implementing the DSM as a prototypical Decision Support Tool (DST), which is a basic for further development of a Decision Support System (DSS). 
This article firstly introduces the term of Decision Support (DS) and DSF. Then it presents building performance and renovation solutions. Thirdly, it describes the development of the DSF. Finally, it concludes with the implementations of the DSF.

\section{Terms introduction}

\section{Decision support and decision support framework}

DS is a broad field concerned with supporting people in making decisions. Unfortunately, it is in fact very loosely defined. Initially, there was a close link between Decision Support and Operations Research and Decision Analysis. Subsequently, DS was coupled with the development of DSS. Nowadays, DS is probably most often associated with integrated usage of Data Warehouses and OLAP (On-Line Analytical Processing) or Modelling and Simulation. DSS is a computer-based tool that supports business or organizational decisionmaking activities. The DSS is differentiated into communication-driven DSS, data-driven DSS, document-driven DSS, knowledge-driven DSS and model-driven DSS. Decision support framework is a model for development of a decision support system. A DSS requires a structured support, with the DS framework includes people, technology, and the development approach.

\section{Building performance}

Building performance is a comprehensive whole building approach aimed at identifying and fixing comfort and energyefficiency problems in a building. Building performance addresses the following parameters in this research: energy performance, thermal performance and maintenance activities.

Energy performance - Energy performance of a building means the amount of energy actually consumed or estimated to meet the energy demand associated with typical usage of a building, which may include heating, cooling, ventilation, hot water and lighting.

Thermal performance is the extent to which a material or building element reduces heat loss. The thermal performance of a building element is described by its U-value $\left(\mathrm{W} / \mathrm{m}^{2} \mathrm{~K}\right)$. Thermal transmittance values (U-values) of envelop materials are used to predict the fuel consumption of buildings. U-value is the measure of the amount of heat loss through an element of construction, such as roof, wall or windows. The lower the U-value, the less energy lost, the better are its insulation characteristics and indoor/thermal performance. 
Maintenance is a major activity in a building's life cycle. In maintaining a building, there are usually several strategic options available to management and many alternative decisions to be considered. In general, maintenance activities can be classified into six types: routine maintenance, emergency maintenance, corrective maintenance, predictive maintenance (also known as Performance-based Maintenance (PBM)), testing or failure-finding and preventive maintenance.

\section{Renovation solutions}

'Core and shell' covers base building elements, such as structure and envelope. Renovation solutions for 'core and shell' of buildings contain thermal insulation (wall insulation, roof insulation and floor insulation), window renewal, air tightness and shading devices. Building service systems are installed to support the required business functions of the building and the needs of the occupiers. Renovation solutions for service systems of buildings contains component insulation (e.g., pipe work/ductwork insulation, boiler insulation, etc.), component replacement (replace the component before it exceeds its technical life span), system improvement (e.g., upgrade fluorescent lamps to T5- a new version of fluorescent lamps designed to optimize energy consumption), Building Management System (install it to monitor/control building performance) and using renewable energy sources (e.g., solar, geothermal, biomass, hydro and wind).

\section{Development of decision support framework}

In this research, a DSF was developed (see Figure 1), which contains two main components: a building performance analysis component and a decision-making component. 'Model-driven' and 'data-driven' are included in the building performance analysis component and a DSM is the decision-making component. Decision support models can condense a lot of information into simple charts that can be used for project implementation and control and enable easier explanations of decision-making procedures, which sketch the strategy drafting process.

The DSF proposes methodologies for the analysis of building performance and a DSM for the process of decision-making. The building performance factors addressed in this research are energy performance (technical parameter), thermal performance (technical parameter) and maintenance activities. Energy performance and thermal performance analyses are based on modelling and simulation methods. Maintenance activities analysis is based on data warehousing and web application methods. A DSM with six sections is developed, including an initial survey of the area conditions, analysis of building performance, consideration of all possible solutions, specification of feasible options, evaluation of the options and selection of the best option. The DSM is implemented as a prototyp- 


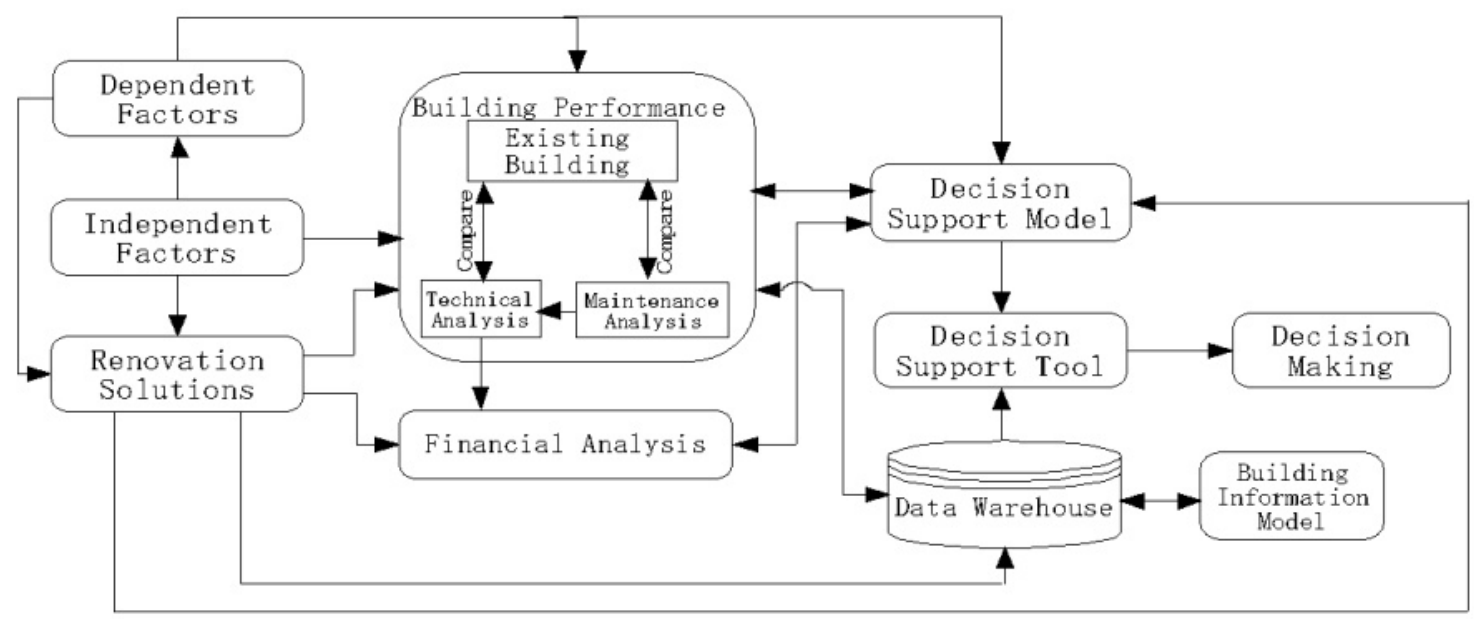

Figure 1: Simplified diagram of the Decision Support Framework (DSF)

ical DST. The DST supports users to make final decisions. Building information model can be used to facilitate accessing, storing and processing all information and linked to a Data Warehouse (DW), which can be available to be used by different stakeholders. The development of the DSF was published in the ASCE Workshop of Computing in Civil Engineering.

\section{Implementations}

In this research, implementation of the DSF proves that the proposed research methodologies for the analysis of building performance and decision support for renovation of a particular building do work. Two case studies are performed for six distinct buildings at UCC and the CEE building located in main campus of UCC.

$\square$ Case study I (six distinct buildings at UCC) - focuses on maintenance activities analysis

$\square$ Case study II (the CEE building at UCC) - focuses on technical parameters analyses

The goal of the first case study is to prioritize what components/systems need to be replaced/renovated. It focuses on renovation strategies from the maintenance density and energy consumption point of view. This case study used six distinct buildings at UCC for analysis of maintenance activities. The six distinct buildings include Kane Building, Boole Library Building, O'Rahilly (O’R) Building, Civil Environmental Engineering (CEE) Building, Electrical Engineering (EE) Building and Environmental Research Institute (ERI) Building. Three of these six buildings are with areas more than $10000 \mathrm{~m}^{2}$ and the other three buildings have smaller areas. Their construction dates vary from 1910 to 2004. By application of the DSF, five suggestions were proposed: optimize the maintenance sched- 
ule of plumbing systems for Boole Building, Kane Building and O'R Building; improve settings of existing Building Management System (BMS) i.e., recalibrate the temperature point for sensors of existing BMS for Boole Building (a BMS is a computer-based control system installed in buildings that controls and monitors the building's performance and energy consumption); upgrade lighting systems for Boole Building, Kane Building, CEE Building and EE Building; improve existing mechanical ventilation systems for Kane Building and CEE Building and improve existing 'core and shell' for CEE Building and EE Building. A Web application was developed to display the frequency of faults and density of maintenance of each building. Future research work is to develop a decision support system based on the DSF that will help engineers easily select a building's components/systems in renovation strategies. This case study was published in the ASCE Workshop of Computing in Civil Engineering in detail.

The purpose of the second case study is to report about the development of an energy simulation model for an existing university building in order to simulate its energy consumption and thermal comfort. This cast study presents a 100-year-old building - the CEE building. It is a traditional structure built in 1910 and in need of substantial renovation. By application of the DSF, there were six renovation solutions initially, but only four renovation solutions were selected because of the limited budget. This case study was published in the International Conference on Building Science and Engineering (ICBSE) in detail.

\section{Conclusions}

There are only few specific guidelines for decision support in building renovation strategies. This research developed a holistic, methodological DSF, which is a guide for the user to analyse building performance for comparison of various renovation solutions in order to make decisions.

I would like to express my sincere gratitude to Professor Karsten Menzel for his supervision and guidance, time, advice and education. I would to thank the Irish Research Council for Science, Engineering \& Technology (IRCSET) programme which supported me in my Ph.D. 